\title{
Bulk-filling of high C-factor posterior cavities: Effect on adhesion to cavity-bottom dentin
}

\author{
Annelies Van Ende, Jan De Munck, Kirsten L. Van Landuyt, André Poitevin, \\ Marleen Peumans, Bart Van Meerbeek*
}

KU Leuven BIOMAT, Department of Oral Health Sciences, KU Leuven (University of Leuven) \& Dentistry, University Hospitals Leuven, Leuven, Belgium

\section{A R T I C L E I N F O}

\section{Article history:}

Received 22 May 2012

Received in revised form

29 October 2012

Accepted 1 November 2012

\section{Keywords:}

Bond strength

Bulk-fill

Composite

Dentin

Micro-tensile

\begin{abstract}
A B S T R A C T
Objectives. To evaluate the effect of bulk-filling high C-factor posterior cavities on adhesion to cavity-bottom dentin.

Methods. A universal flowable composite (G-ænial Universal Flo, GC), a bulk-fill flowable base composite (SDR Posterior Bulk Fill Flowable Base, Dentsply) and a conventional pastelike composite (Z100, 3M ESPE) were bonded (G-ænial Bond, GC) into standardized cavities with different cavity configurations (C-factors), namely $C=3.86$ (Class-I cavity of $2.5 \mathrm{~mm}$ deep, bulk-filled), $C=5.57$ (Class-I cavity of $4 \mathrm{~mm}$ deep, bulk-filled), $C=1.95$ (Class-I cavity of $2.5 \mathrm{~mm}$ deep, filled in three equal layers) and $C=0.26$ (flat surface). After one-week water storage, the restorations were sectioned in 4 rectangular micro-specimens and subjected to a micro-tensile bond strength ( $\mu$ TBS) test.

Results. Highly significant differences were found between pairs of means of the experimental groups (Kruskal-Wallis, $p<0.0001$ ). Using the bulk-fill flowable base composite SDR (Dentsply), no significant differences in $\mu$ TBS were measured among all cavity configurations ( $p>0.05$ ). Using the universal flowable composite G-ænial Universal Flo (GC) and the conventional paste-like composite Z100 (3M ESPE), the $\mu$ TBS to cavity-bottom dentin was not significantly different from that of SDR (Dentsply) when the cavities were layer-filled or the flat surface was build up in layers; it was however significantly lower when the Class-I cavities were filled in bulk, irrespective of cavity depth.

Significance. The filling technique and composite type may have a great impact on the adhesion of the composite, in particular in high C-factor cavities. While the bulk-fill flowable base composite provided satisfactory bond strengths regardless of filling technique and cavity depth, adhesion failed when conventional composites were used in bulk.
\end{abstract}

(c) 2012 Academy of Dental Materials. Published by Elsevier Ltd. All rights reserved.

\section{Introduction}

'Flowables' are low-viscosity composites obtained from formulations with a filler loading that is $20-25 \%$ lower than that of conventional composites [1]. They possess a good wetting ability, which favors their adaptation to the cavity walls, and are therefore expected to decrease the risk for air entrapment and void inclusion [2,3]. However, the first-generation flowable composites were not suitable for full-depth posterior fillings

* Corresponding author at: KU Leuven BIOMAT, Department of Oral Health Sciences, KU Leuven (University of Leuven), Kapucijnenvoer 7, blok a - bus 7001, B-Leuven, Belgium. Tel.: +32 1633 75 87; fax: +32 16332752 .

E-mail address: bart.vanmeerbeek@med.kuleuven.be (B. Van Meerbeek).

0109-5641/\$ - see front matter @ 2012 Academy of Dental Materials. Published by Elsevier Ltd. All rights reserved.

http://dx.doi.org/10.1016/j.dental.2012.11.002 


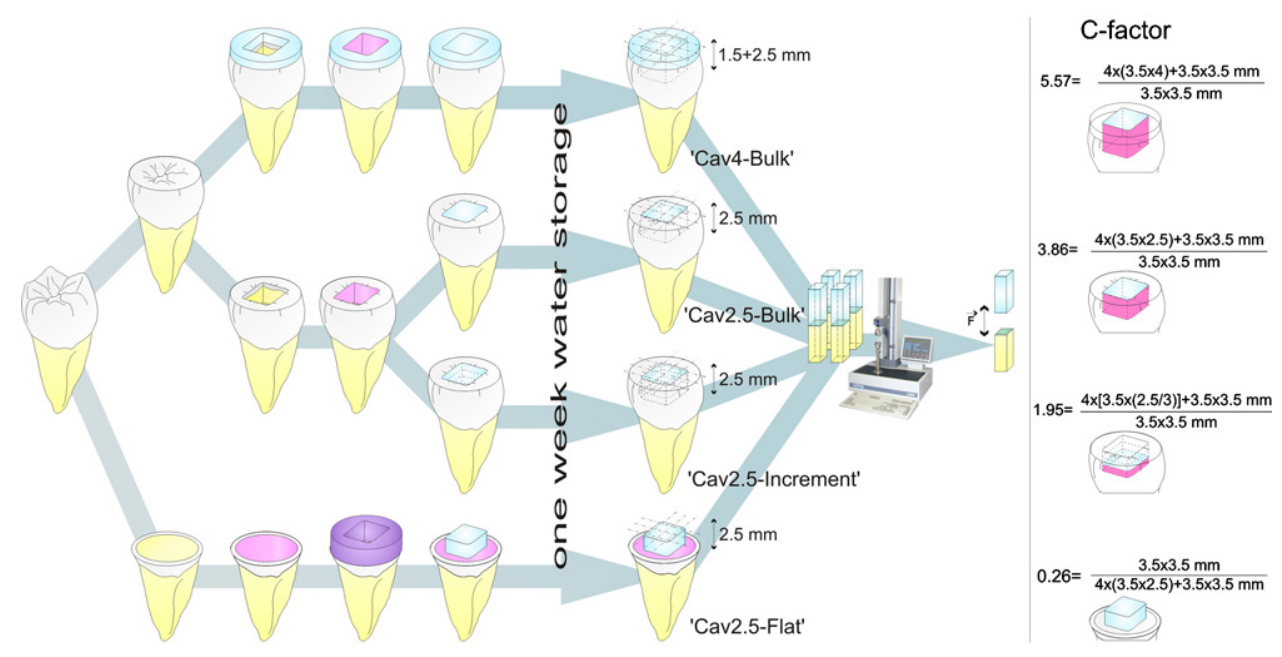

Fig. 1 - Scheme explaining the study set. Standardized samples (8 per group) were prepared with a computer-controlled device and filled according to one of the four experimental groups. After one-week water storage, $1 \mathrm{~mm} \times 1 \mathrm{~mm}$ adhesive-dentin micro-specimens (4 per tooth) were prepared and stressed in tension until failure.

because of their inferior mechanical properties and increased volumetric shrinkage compared to conventional paste-like composites, primarily due to the lower filler content [1-4]. Basically, they could only be applied as liner or sealer, or to restore very small cavities $[1,5]$. As dental industry constantly searches for materials with improved properties, the latest generations of flowable composites have higher filler content and are claimed to have increased mechanical properties; they thus are now also recommended for larger posterior restorations [6]. To further simplify the filling procedure (and to save precious chair time), the latest trend in composite technology is the development of flowable restorative composites that can be placed in bulk up to $4 \mathrm{~mm}$ thickness [7-9]. Posterior bulk-filling was introduced with the flowable composite 'SDR Posterior Bulk Fill Flowable Base' (Dentsply, Konstanz, Germany; in US: SureFil SDR Flow); it still requires a conventional paste-like composite to be placed/cured on top of the 4-mm thick composite base. Due to an enhanced translucency and by incorporating a photoactive group in the methacrylate resin (according to technical information from Dentsply), polymerization kinetics are claimed to be better controlled, enabling the composite base to be injected and cured in bulk up to a depth of $4 \mathrm{~mm}$ In the few studies that investigated this flowable composite base, polymerization stress was indeed reported to be considerably lower than that of a conventional flowable composite, being comparable to that of marketed low-shrinking composites [10-12], and marginal integrity appeared as good as that obtained with a conventionally layered composite $[8,10]$.

Up to now, an incremental layering technique has been the standard to prevent gap formation due to polymerization stress and to achieve an adequate bonding of composite to tooth tissue [12-14]. In order to test whether or not we can discard the incremental steps and fill the cavity at once, the performance of contemporary flowable composites for posterior restorations needs to be evaluated in deep and narrow cavities. These cavities have a high C-factor [15], where stress relief due to flow is severely limited and the contraction stress might exceed the bond strength [16]. Moreover, mechanical properties of the composite most close to the interface might be compromised if the curing light loses too much intensity due to attenuation before reaching the bottom of the cavity [17].

Therefore, the objective of this study was to compare the performance of a universal flowable composite, a bulk-fill flowable base and a conventional paste-like composite in cavities with different $\mathrm{C}$-factors. The null-hypothesis was that the micro-tensile bond strength ( $\mu$ TBS) to dentin does neither depend on the C-factor of the cavity, nor on the used composite.

\section{Materials and methods}

The study set-up is schematically illustrated in Fig. 1 and the materials that have been used are listed in Table 1 . Ninetysix non-carious human third molars were stored in $0.5 \%$ chloramine solution at $4{ }^{\circ} \mathrm{C}$ and used within 2 months after extraction. All teeth were mounted in gypsum blocks in order to ease manipulation. All groups were randomly subdivided in four subgroups. In three subgroups ('Cav'), standard box-type Class-I cavities $(3.5 \mathrm{~mm} \times 3.5 \mathrm{~mm})$ were prepared. The depth of these cavities was $2.5 \mathrm{~mm}$ in two subgroups ('Cav2.5') and $4 \mathrm{~mm}$ in one subgroup ('Cav4'). The latter 4-mm deep cavities were obtained by first building up the molar teeth using the nano-hybrid composite Filtek Supreme XTE (3M ESPE, Seefeld, Germany) in a contrasting shade (A4), after which the cavities were prepared as detailed underneath. In this way, the cavitybottom dentin in all cavity types (including the flat surface) was mid-coronal, ensuring that effects of regional variability on $\mu$ TBS $[16,18]$ were negligible. The $\mathrm{C}$-factor was calculated as the ratio between bonded and unbonded surfaces, as shown in Fig. 1 [15]. The resulting C-factors of the 2.5- and 4-mm cavities were 3.86 and 5.57 , respectively. The $2.5-\mathrm{mm}$ depth was chosen because this is the maximum curing depth recommended by the manufacturer of the conventional composite that served 
Table 1 - Overview of the experimental groups.

\begin{tabular}{|c|c|c|c|c|}
\hline Material & Composition & Filler load & Maximum layer thickness & Batch no. \\
\hline \multicolumn{5}{|l|}{ Composite } \\
\hline G-ænial & Matrix: urethane dimethacrylate, & $69 \mathrm{wt} \%$ & $1.5 \mathrm{~mm}$ & LOT 1011091 \\
\hline $\begin{array}{l}\text { Universal Flo } \\
\text { (GC) }\end{array}$ & $\begin{array}{l}\text { Bis-MEPP, TEG-DMA, pigment; } \\
\text { photo-initiator } \\
\text { Filler: } \mathrm{SiO}_{2}(16 \mathrm{~nm}), \mathrm{Sr} \text { glass } \\
(200 \mathrm{~nm})\end{array}$ & 50 vol\% & & \\
\hline SureFil SDR & Matrix: SDR patented urethane & $68 w t \%$ & $4 \mathrm{~mm}$ & LOT 1104001464 \\
\hline Flow (Dentsply) & $\begin{array}{l}\text { dimethacrylate, dimethacrylate, } \\
\text { ethoxylated bisphenol A } \\
\text { dimethacrylate, pigment, } \\
\text { photoinitiator } \\
\text { Filler: barium and strontium } \\
\text { alumino-fluoro-silicate glasses }\end{array}$ & 45 vol\% & & \\
\hline Filtek Z100 (3M & Matrix: Bis-GMA, TEG-DMA, & $84.5 \mathrm{wt} \%$ & $2.5 \mathrm{~mm}$ & LOT 20091001 \\
\hline ESPE) & $\begin{array}{l}\text { pigment, photo-initiator } \\
\text { Filler: silica/zirconia }(600 \mathrm{~nm})\end{array}$ & 71 vol\% & & \\
\hline \multicolumn{5}{|l|}{ Adhesive } \\
\hline $\begin{array}{l}\text { G-ænial Bond } \\
\text { (GC) }\end{array}$ & $\begin{array}{l}\text { Phosphoric ester monomer, 4-MET, } \\
\text { hydrophilic methacrylate } \\
\text { monomer, water, acetone, } \\
\text { photo-initiator, nano-silica }\end{array}$ & & & LOT 1012181 \\
\hline
\end{tabular}

as control (Z100, 3M ESPE). Next, the 2.5-mm deep cavities were filled either in bulk ('Cav2.5-Bulk') or increments (in three equal horizontal layers 'Cav2.5-Increment'). Incremental filling decreases the C-factor per layer until approximately 1.95 and the volume is divided by three. The 4-mm deep cavities were filled in bulk ('Cav4-Bulk'). In the fourth subgroup, flat surfaces were prepared at a depth of $2.5 \mathrm{~mm}$ ('Flat2.5-Bulk') and a $3.5 \mathrm{~mm} \times 3.5 \mathrm{~mm}$ build-up was made in bulk $(2.5 \mathrm{~mm}$ high) using a silicone mold (C-factor $=0.26$, but with the same volume and dimensions as 'Cav2.5-Bulk'). All preparations were made with a computer-controlled, custom-adapted automatic device (OES Allegra Controller, Trol-Mation Inc., Syracuse, NY, USA), equipped with a cylindrical medium-grit diamond bur (835 314 010, Komet, Lemgo, Germany) mounted in a high-speed air turbine (650, KaVo, Biberach, Germany). A one-step self-etch adhesive was used in all experimental groups (G-ænial Bond, GC, Tokyo, Japan) according to the manufacturer's instructions. The teeth were randomly divided in three subgroups according to the composite used, resulting in 8 teeth per subgroup. Two flowable composites for posterior filling ('GUF', G-ænial Universal Flo, GC; 'SDR', SureFil SDR Flow, Dentsply) and a conventional micro-hybrid composite ('Z100', Filtek Z100, 3M ESPE) were used (shade A3, except for SDR, which is only available in one shade). The restoration was light-cured with a high-power LED curing device (Bluephase, Ivoclar Vivadent, Schaan, Liechtenstein) with an output of at least $900 \mathrm{~mW} / \mathrm{cm}^{2}$ (40 s in the bulk groups 'Bulk'; 20 s per layer in the incremental group 'Increment'). The light intensity was checked before and after each use with the accompanying Bluephase meter (Ivoclar Vivadent).

After one week of water storage at $37^{\circ} \mathrm{C}$, the teeth were sectioned perpendicular to the adhesive-tooth interface using an automated water-cooled diamond saw (Accutom-50, Struers, Ballerup, Denmark) to obtain rectangular $1 \mathrm{~mm} \times 1 \mathrm{~mm}$, non-trimmed micro-specimens for $\mu$ TBS testing. The specimens were examined light-microscopically (MSA 166305 stereomicroscope, Wild Heerbrugg, Switzerland) at a magnification of $50 x$ to check for the presence of air bubbles or cavity border at the specimen's interface; these samples were excluded from further testing. The specimens were kept moisturized until tested. They were attached to a notched BIOMAT-jig [19] with cyanoacrylate glue (Model Repair II Blue, Sankin Kogyo, Tochigi, Japan) and stressed at a crosshead speed of $1 \mathrm{~mm} / \mathrm{min}$ until failure in a LRX testing device (LRX, Lloyd, Hampshire, UK) using a load cell of $100 \mathrm{~N}$. The $\mu$ TBS was expressed in $\mathrm{MPa}$, as derived from dividing the imposed force $(\mathrm{N})$ at the time of fracture by the bond area $\left(\mathrm{mm}^{2}\right)$. When specimens failed before actual testing (pre-testing failure: 'ptf'), they were recorded as zero for further statistical analysis.

The mode of failure was assessed light-microscopically (MSA 166305 stereomicroscope) at a magnification of 50×. Per micro-specimen, occurrence of 'cohesive failure in dentin', 'adhesive failure at the interface', 'cohesive failure in composite' or 'mixed failure' was recorded. A failure was classified as 'mixed' when a larger region from the surface $(>10 \%)$ also included cohesive failure in dentin and/or resin. From all groups, some representative fracture surfaces, originating from at least two teeth, were processed for a more in-depth analysis using scanning electron microscopy (JSM-6610LV SEM, JEOL, Tokyo, Japan) after common SEM preparation techniques, including fixation in $2.5 \%$ glutaraldehyde in cacodylate buffer solution, dehydration in ascending concentrations of ethanol, chemical drying using hexamethyldisilazane, and gold-sputter coating [20].

Micro-tensile bond strength data ( $\mu$ TBS per microspecimen in $\mathrm{MPa}$ ) were analyzed by Kruskal-Wallis, preceding post hoc multiple comparisons at $p<0.05$ (Statistica 10, StatSoft, Tulsa, USA). To estimate bonding performance, the data were also analyzed using Weibull statistics and pivotal confidence bounds were calculated using Monte Carlo simulation [21]. Different groups were compared at the $10 \%$ unreliability levels (B10) and at the characteristic strength ( $\eta$, scale, also 


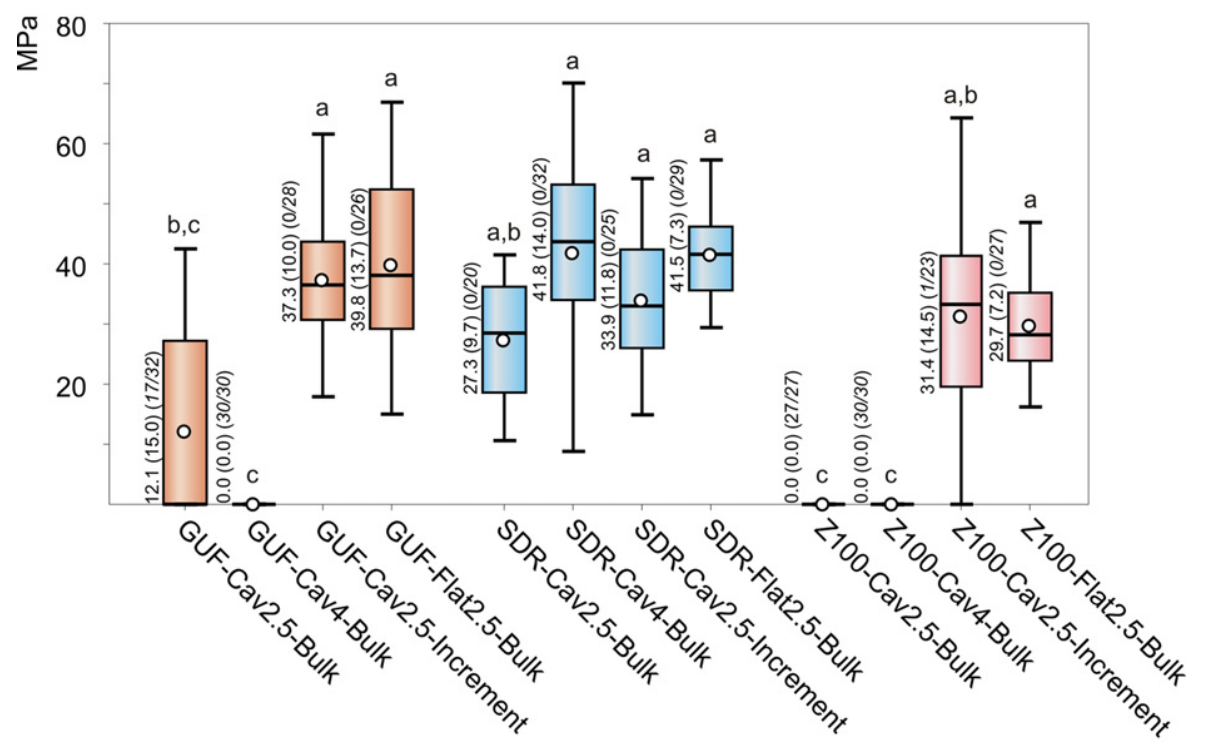

Fig. 2 - Boxplot of the $\mu$ TBS results. The box represents the spreading of the data between the first and third quartile. The central horizontal line and the circle represent the median and mean, respectively. The whiskers extend to the minimum and maximum value measured. Groups with the same letter are not statistically significantly different $(p<0.05)$.

63.2\% unreliability). The slope of the Weibull distribution curve is referred to as $\beta$, which is related to reliability. Pre-testing failures were excluded from the Weibull analysis, as Weibull cannot operate with zero values. When fracture occurred 'cohesively' in dentin or in composite, yet close to the interface so that it could not be re-glued but not involving the interface, the obtained value was considered as right-censored. All tests were performed at a significance level of $\alpha=0.05$ using a software package (R2.12 and Weibull Toolkit 2.1, R Foundation for Statistical Computing, Vienna, Austria and weibulltoolkit 2.1, http://sourceforge.net/projects/weibulltoolkit).

\section{Results}

$\mu$ TBS-values ranged from $0 \mathrm{MPa}$ (pre-testing failure) to 70.1 MPa, as shown in Fig. 2. When the cavities were filled in increments or when the composite was built upon a flat surface, no significant differences were found between the different composites $(p>0.05)$. However, for the conventional flowable and paste-like composite, bulk-filling of a cavity resulted in a highly significant decrease in bond strength $(p<0.001)$. Moreover, $53 \%$ of the 'GUF-Cav2.5-Bulk' specimens and all the 'GUF-Cav4-Bulk', 'Z100-Cav2.5-Bulk' and 'Z100Cav4-Bulk' specimens failed before testing. With the flowable bulk-fill base, however, the bond strengths were maintained and no pre-testing failures were recorded.

Results of the Weibull statistics are presented in Fig. 3. Characteristic strength ranged from $29.6 \mathrm{MPa} \mathrm{m}^{-1 / 2}$ ('GUFCav2.5-Bulk') to $54.4 \mathrm{MPa} \mathrm{m}^{-1 / 2}$ ('SDR-Cav4-Bulk'). Analysis of 'GUF-Cav4-Bulk', 'Z100-Cav2.5-Bulk' and 'Z100-Cav4-Bulk' was not performed (100\% ptf). Higher slopes were recorded for 'Cav2.5-Increment' and 'Flat2.5-Bulk', irrespective of the composite used.

Surface analysis revealed that pre-testing failures occurred predominantly 'adhesively at the interface', while in the other groups all types of failures were seen. With the flowable bulkfill base SDR (Dentsply), more 'cohesive failures in composite' were recorded (Figs. 4 and 5).

\section{Discussion}

'Bulk-filling' is highly desired in routine restorative practice, but concerns about shrinkage stress have caused certain reluctance in its application. To overcome the negative effects of polymerization shrinkage, low-shrinking composites have been developed with reasonable success; different brands were marketed, making use of either totally new (usually ringopening) monomer technology, like the so-called Siloranes [22], or adapted (usually higher molecular weight) methacrylate monomer technology $[23,24]$. Nevertheless, low-shrinking composites did not become a huge breakthrough, as they hardly became the material of choice to restore posterior teeth [25]. This might be attributed to several factors; first, the high viscosity and stickiness of the uncured resin can make insertion in the cavity difficult and unpredictable [26-28]. On top of that, new low-shrinking matrix formulations potentially need a different adhesive [22]. Secondly, due to the modified resin formulations, sometimes a compromise has to be made to the detriment of the esthetic properties [29,30]. Finally, the clinical advantage of using a low-shrinking composite is not always directly visible [31,32], all the more because incremental filling technique is most often still needed, mainly due to reduced polymerization efficiency with depth [33,34].

Following the trend of 'low-shrinking' composite technology, the demand for bulk-filling has more recently been approached with the introduction of flowable composites that can be placed and cured in one layer of up to a thickness of $4 \mathrm{~mm}$ [9]. Although flowable composites generally shrink more than conventional paste-like composites [1,4], their resulting shrinkage stress remains comparatively low [5]. This should 

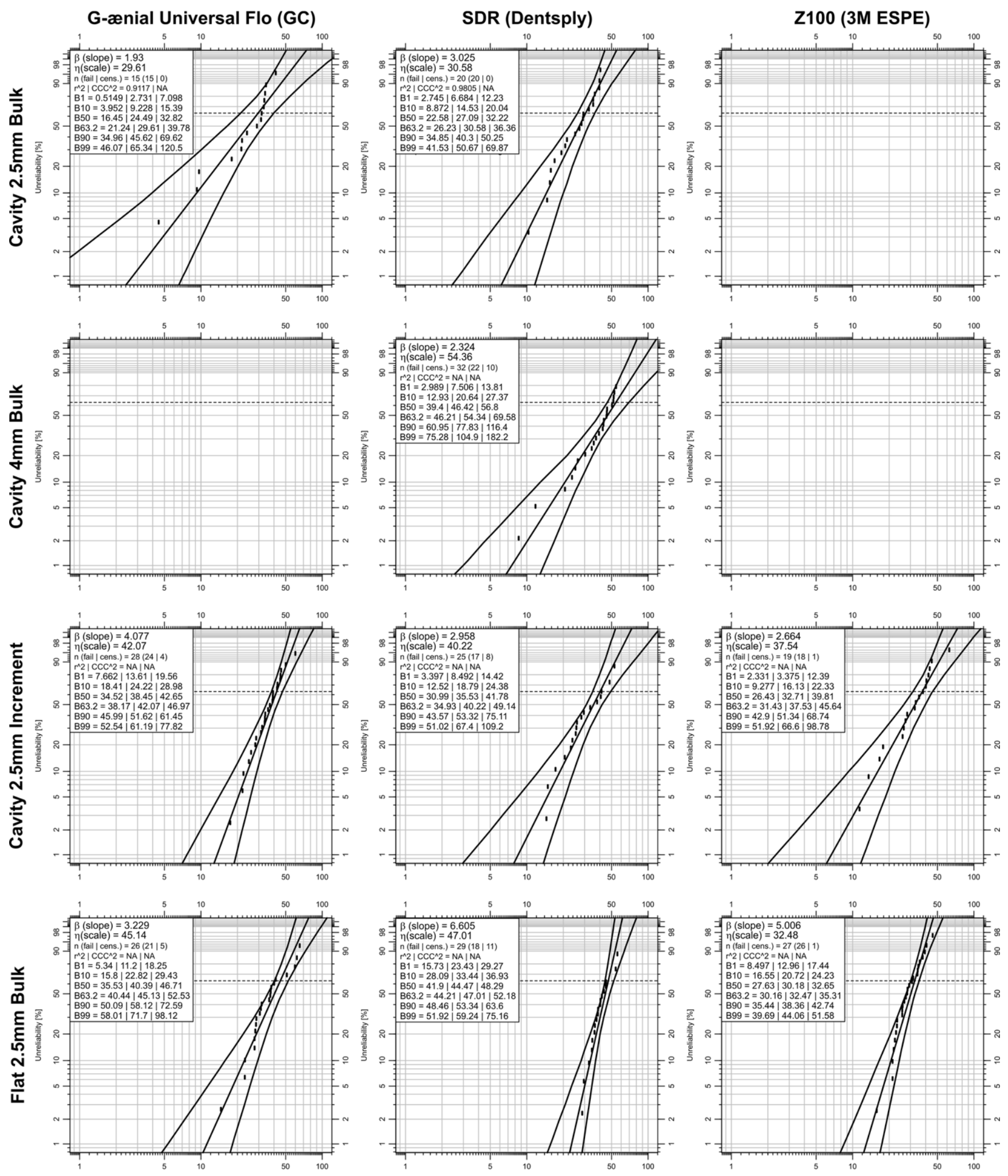

Fig. 3 - Weibull plots for the four experimental groups per composite tested, with the exception of 3 groups, in which $100 \%$ pre-testing failures were recorded and hence no Weibull analysis could be done.

mainly be attributed to the highly stress-relieving internal monomer flow prior to reaching the gel-point, the moment at which stress starts to build up $[35,36]$. The first flowable bulk-fill concept was introduced with 'SDR' (Dentsply); it consists of a two-stage procedure, involving the placement and curing of an up to 4-mm thick flowable composite base that subsequently is covered by a conventional composite placed/cured on top. Bulk-filling is possible thanks 


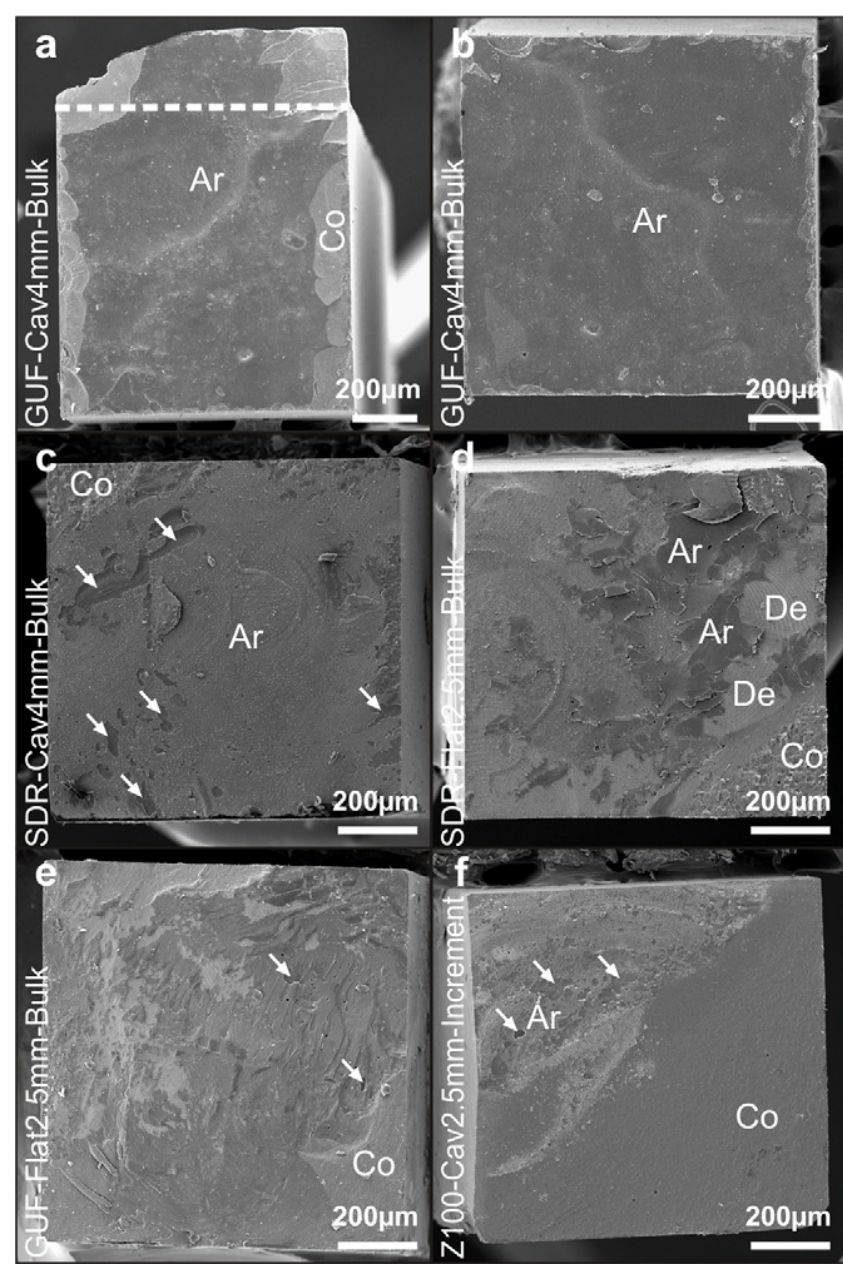

Fig. 4 - SEM photomicrographs of $\mu$ TBS-fractured surfaces. (a and b) Pre-testing failure recorded for

'GUF-Cav4mm-Bulk'. Failure occurred 'cohesively within the adhesive'. (a) Composite side, covered almost entirely with adhesive resin (Ar). The surface is rectangle-shaped (and not square-shaped) because the failure occurred before the last cut during micro-specimen preparation was completed. (b) Dentin side, covered almost entirely with adhesive resin. (c) 'Mixed' failure recorded for 'SDR-Cav4mm-Bulk', presenting the composite side. Many large voids are visible within the adhesive layer (arrows). As failure occurred mainly at the interface, some imprints of the dentin tubuli are visible. In the corner of the specimen, part of the relatively coarsely structured composite (Co) is visible. (d) 'Mixed' failure recorded for 'SDR-Flat2.5mm-Bulk', presenting the dentin side. Tiny bubbles are located within the adhesive layer. Circular bur scratches can be seen at the dentin (De) part of the interface. (e) 'Mixed' failure recorded for

'GUF-Flat2.5mm-Bulk' that failed for the largest part in the porous (arrows) adhesive resin. (f) 'Mixed' failure recorded for 'Z100-Cav2.5mm-Increment', composite side. Fracture occurred mostly cohesively within the composite and within the adhesive resin close to the interface. Ar: adhesive resin; Co: composite; De: dentin.

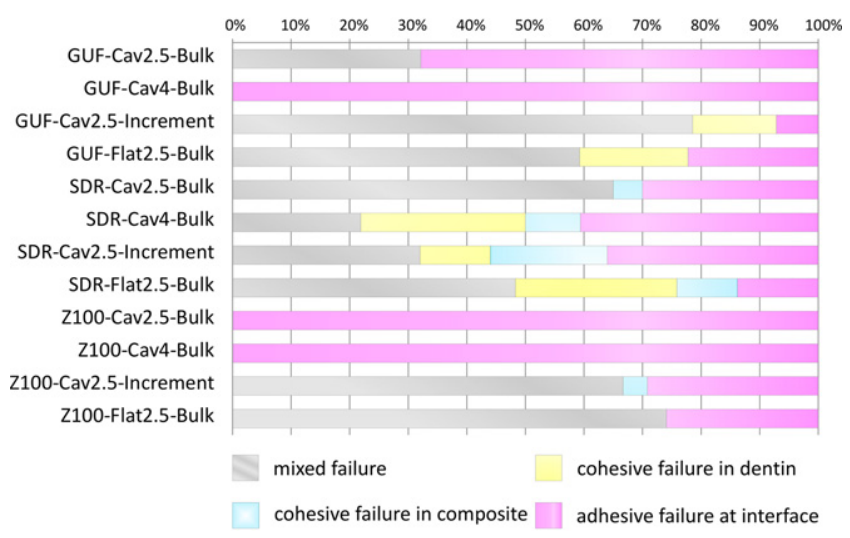

Fig. 5 - Fracture analysis presenting the distribution of failure modes for the 12 experimental groups.

to the abovementioned stress-relieving flow-ability, potentially enhanced by a so-termed 'polymerization modulator', as claimed by the manufacturer (Dentsply) "to be chemically embedded in the polymerizable resin backbone of the 'SDR' resin monomer" [11]. SDR's enhanced translucency [37] promotes light transmittance and thus enables adequate curing efficiency up to a layer thickness of $4 \mathrm{~mm}$ at maximum. Newer launched products even proclaim full-depth bulk-filling up to $4 \mathrm{~mm}$ (Tetric EvoCeram Bulk Fill, Ivoclar-Vivadent, Schaan, Liechtenstein), and $5 \mathrm{~mm}$ (SonicFILL, Kerr, Orange, CA, USA).

In this study, we opted to employ a micro-tensile bond strength protocol to evaluate the potential impact of bulkfilling on the bond strength to dentin in different C-factor cavities. The flowable bulk-fill composite base SDR (Dentsply) was evaluated in comparison with a conventional flowable and paste-like composite that served as controls. It was assumed that polymerization shrinkage stress would impose tensile stress to the adhesive interface at cavity-bottom dentin and thus affect the bond integrity. The latter effect was measured in terms of $\mu$ TBS. A representative one-step adhesive (G-ænial Bond, GC) was selected because of its favorable laboratory [38] and clinical data [39], well realizing that a twostep self-etch or a three-step etch-and-rinse adhesive would likely have performed better [40-43]. However, any detrimental effects of high C-factor cavity configuration and increased light attenuation with depth on the integrity of the adhesive interface might have been less apparent with such multi-step adhesives. Finally, we opted for a one-step self-etch adhesive, as the current market trend clearly goes toward simple and easy-to-use adhesive application protocols.

When the three composites were built upon a flat surface or used to fill the $(2.5-\mathrm{mm})$ cavities in (three) increments, no significant differences in $\mu$ TBS were found among the composites $(p>0.05)$. Moreover, both filling techniques provided higher bond strength reliability, as is reflected in the steeper Weibull slopes (Fig. 3). This confirms once again that a layered-filling approach remains the standard for posterior composite restorations. When a $2.5-\mathrm{mm}$ build-up was made in bulk on a flat surface, the C-factor was reduced to 0.26 , while the composite volume and depth of cure were maintained because the used silicon mold had the exact same dimensions 
as the cavity. When the $2.5-\mathrm{mm}$ deep cavities were filled in three increments, both the $\mathrm{C}$-factor and the composite volume were reduced. Both might have reduced the shrinkage stress imposed onto the adhesive interface at the cavity bottom. In addition, less blue light was attenuated at the cavity bottom when curing the first increment, by which the composite just above the adhesive interface must have been polymerized adequately, this to the direct benefit of the mechanical strength of the bond to cavity-bottom dentin [17,44-46].

Regarding the conventional flowable composite G-ænial Universal Flo (GC), it is additionally noteworthy to mention that even though only thin increments of maximum $1.5 \mathrm{~mm}$ are recommended by the manufacturer of G-ænial Universal Flo (GC; see Table 1), the bond strength was not negatively affected when a $2.5-\mathrm{mm}$ build-up was made on a flat surface ('GUF-Flat2.5mm-Bulk').

When the 2.5-mm deep cavities were restored in bulk, the high constraint in these narrow cavities evoked high polymerization stress within two out of the three tested composites, and because of which the adhesive interface appeared less or even not resistant. With the conventional flowable composite (G-ænial Universal Flo, GC), this challenge to the interface caused $53 \%$ of the specimens to fail before testing, causing a significant drop in the bond strength compared to incremental filling $(p<0.0001)$ or when the composite was build up on a flat surface $(p=0.00028)$. Even worse were the results recorded for the conventional paste-like composite (Z100, 3M ESPE), of which all specimens failed during specimen processing $(100 \%$ pre-testing failures for ' $\mathrm{Z} 100-\mathrm{Cav} 2.5 \mathrm{~mm}$-Bulk'). The composite Z100 (3M ESPE), which was used as control, is well known to generate high shrinkage stress $[47,48]$. Although less pretesting failures and thus a higher mean $\mu$ TBS were recorded for the conventional flowable composite (G-ænial Universal Flo, GC) than for the conventional paste-like composite (Z100, 3M ESPE), this difference between 'GUF-Cav2.5mm-Bulk' and 'Z100-Cav2.5mm-Bulk' was not statistically significant. An explanation for the difference might nevertheless be found in the difference in internal stress-relieving capacity prior to reaching the gel-point, as it was mentioned above. On the contrary, the bulk-fill flowable base (SDR, Dentsply) could maintain its bond strength without any pre-testing failures. Hence, no significant difference in $\mu$ TBS was recorded with the 'SDR' incrementally filled cavities $(p=1.00)$ and the flat-surface build-ups $(p=0.255)$, but also with the two respective experimental groups for the conventional flowable (G-ænial Universal Flo, GC) and paste-like composite (Z100, $3 \mathrm{M}$ ESPE). It had already been confirmed in previous materialcharacterization studies that SDR (Dentsply) generates lower polymerization stresses $[10,12]$. As the cavity depth was only $2.5 \mathrm{~mm}$, potential reduction in curing efficiency due to light attenuation was expected to have only been involved minimally.

The configuration of the 4-mm deep cavities was the least favorable, not only because it has a higher C-factor and restoration volume, but also because the maximum curing depth for conventional composites was exceeded. It must therefore be stressed that the manufacturer of both the conventional flowable and paste-like composites tested, as well as of most posterior composites, do not recommend to fill deep cavities in bulk (see Table 1), yet this was done for the research objectives of this study. Hence, the high C-factor induced polymerization stress [15]. Furthermore, as a result of absorption and scattering by the overlaying composite, the intensity of the blue curing light was seriously hampered at the 4-mm deep cavity bottom $[49,50]$. Consequently, all 'GUF-Cav4mm-Bulk' and 'Z100-Cav4mm-Bulk' specimens failed before testing (100\% pre-testing failures). Again, a high bond strength was maintained for 'SDR-Cav4mm-Bulk' and appeared not significantly different from that recorded for 'SDR-Cav2.5mm-Increment' and 'SDR-Flat2.5mm-Bulk' (both $p=1.00$ ). This favorable data imply that this bulk-fill flowable base SDR (Dentsply) can be cured in bulk without harming the bond to cavity-bottom dentin. In previous research, it was already confirmed that the mechanical properties of SDR (Dentsply) are maintained at $4 \mathrm{~mm}$ depth after curing in bulk $[11,51]$.

Fracture analysis (Fig. 5) revealed that higher bond strengths were often associated with 'mixed' or 'cohesive' failures in dentin or composite. On the contrary, pre-testing failures always occurred 'adhesively at the interface' or more precisely 'cohesively' within the upmost part of the adhesive layer (Fig. 4a and b), leaving both fracture surfaces covered with adhesive remnants. This may indicate that de-bonding due to shrinkage may have occurred within the soft and sticky oxygen-inhibition layer [52] that was detached from the cured part of the adhesive layer when the composite retracted from the cavity bottom during polymerization. On the contrary, in groups where SDR (Dentsply) was used, failures appeared predominantly 'cohesive within the composite' (Fig. 5). This may indicate that the exhibited stress had exceeded the tensile strength of the composite before the actual bond strength was challenged. Since these failures were mostly associated with higher MPa-values, it would be overhasty to conclude that its tensile strength would be lower than that of the other composites tested.

Finally, the one-step self-etch adhesive used (G-ænial Bond, GC) should be, according to the manufacturer's instructions, strongly air-thinned. While this is very feasible on a flat surface, ensuring a rather thin and more uniform adhesive layer, the spreading of the adhesive on the bottom of the narrow Class-I cavity was limited; we could not avoid to have produced a more variable and generally thicker layer with even pooling of the adhesive in the cavity corners to some extent [53]. Such an excess of adhesive has been reported to negatively influence the bond strength [54]. Moreover, this HEMA-free one-step adhesive (G-ænial Bond, GC), is known to induce phase separation and therefore requires post-application 'strong' air-thinning [55]. Nevertheless, within more difficult cavity configurations like the Class-I cavities in this study, but also within Class-II cavities, application of the adhesive cannot be controlled very well, causing more voids and porosities to become entrapped within the adhesive layer, as can be seen in Fig. 4.

\section{Conclusion}

The null-hypothesis had to be rejected, since highly significant results were found between pairs of means of the experimental groups (Kruskal-Wallis, $p<0.001$ ). Satisfactory bond 
strengths were obtained when an incremental filling technique was employed and when a build-up was made on a low C-factor flat surface. These techniques appeared also most reliable for all composites. However, when high C-factor cavities are filled in bulk, the choice of the composite will be important in order to avoid adhesive de-bonding.

\section{Acknowledgements}

Drs. A. Van Ende has been granted a PhD fellowship of the Flanders Research Foundation (FWO). The dental companies 3M ESPE, Dentsply and GC are gratefully acknowledged for the generous donation of materials for this study.

\section{REFERENCES}

[1] Bayne SC, Thompson JY, Swift Jr EJ, Stamatiades P, Wilkerson M. A characterization of first-generation flowable composites. Journal of the American Dental Association 1998;129:567-77.

[2] Lee IB, Min SH, Kim SY, Ferracane J. Slumping tendency and rheological properties of flowable composites. Dental Materials 2010;26:443-8.

[3] Chuang SF, Liu JK, Chao CC, Liao FP, Chen YH. Effects of flowable composite lining and operator experience on microleakage and internal voids in class II composite restorations. Journal of Prosthetic Dentistry 2001;85:177-83.

[4] Labella R, Lambrechts P, Van Meerbeek B, Vanherle G. Polymerization shrinkage and elasticity of flowable composites and filled adhesives. Dental Materials 1999;15:128-37.

[5] Braga RR, Hilton TJ, Ferracane JL. Contraction stress of flowable composite materials and their efficacy as stress-relieving layers. Journal of the American Dental Association 2003;134:721-8.

[6] Ikeda I, Otsuki M, Sadr A, Nomura T, Kishikawa R, Tagami J. Effect of filler content of flowable composites on resin-cavity interface. Dental Materials Journal 2009;28:679-85.

[7] Fleming GJ, Awan M, Cooper PR, Sloan AJ. The potential of a resin-composite to be cured to a $4 \mathrm{~mm}$ depth. Dental Materials 2008;24:522-9.

[8] Roggendorf MJ, Krämer N, Appelt A, Naumann M, Frankenberger R. Marginal quality of flowable 4-mm base vs. conventionally layered resin composite. Journal of Dentistry 2011;39:643-7.

[9] Burgess J, Cakir D. Comparative properties of low-shrinkage composite resins. Compendium of Continuing Education in Dentistry 2010;31:10-5.

[10] Moorthy A, Hogg CH, Dowling AH, Grufferty BF, Benetti AR, Fleming GJ. Cuspal deflection and microleakage in premolar teeth restored with bulk-fill flowable resin-based composite base materials. Journal of Dentistry 2012;40:500-5.

[11] Ilie N, Hickel R. Investigations on a methacrylate-based flowable composite based on the SDR ${ }^{\mathrm{TM}}$ technology. Dental Materials 2011;27:348-55.

[12] Rullmann I, Schattenberg A, Marx M, Willershausen B, Ernst CP. Photoelastic determination of polymerization shrinkage stress in low-shrinkage resin composites. Schweizer Monatsschrift fur Zahnmedizin 2012;122:294-9.

[13] Park J, Chang J, Ferracane J, Lee IB. How should composite be layered to reduce shrinkage stress: incremental or bulk filling? Dental Materials 2008;24:1501-5.
[14] Kim ME, Park SH. Comparison of premolar cuspal deflection in bulk or in incremental composite restoration methods. Operative Dentistry 2011;36:326-34.

[15] Feilzer AJ, De Gee AJ, Davidson CL. Setting stress in composite resin in relation to configuration of the restoration. Journal of Dental Research 1987;66:1636-9.

[16] Yoshikawa T, Sano H, Burrow MF, Tagami J, Pashley DH. Effects of dentin depth and cavity configuration on bond strength. Journal of Dental Research 1999;78:898-905.

[17] Peutzfeldt A, Asmussen E. Resin composite properties and energy density of light cure. Journal of Dental Research 2005;84:659-62.

[18] Toledano M, Osorio R, Ceballos L, Fuentes MV, Fernandes CA, Tay FR, et al. Microtensile bond strength of several adhesive systems to different dentin depths. American Journal of Dentistry 2003;16:292-8.

[19] Poitevin A, De Munck J, Van Landuyt K, Coutinho E, Peumans $\mathrm{M}$, Lambrechts $\mathrm{P}$, et al. Critical analysis of the influence of different parameters on the microtensile bond strength of adhesives to dentin. Journal of Adhesive Dentistry 2008;10:7-16.

[20] Perdigão J, Lambrechts P, Van Meerbeek B, Vanherle G, Lopes AL. Field emission SEM comparison of four postfixation drying techniques for human dentin. Journal of Biomedical Materials Research 1995;29:1111-20.

[21] Symynck J, De Bal F. Monte Carlo pivotal confidence bounds for Weibull analysis, with implementations in R. Tehnomus 2011;18:44-50.

[22] Weinmann W, Thalacker C, Guggenberger R. Siloranes in dental composites. Dental Materials 2005;21:68-74.

[23] Yap AU, Soh MS. Post-gel polymerization contraction of "low shrinkage" composite restoratives. Operative Dentistry 2004;29:182-7.

[24] Papadogiannis D, Tolidis K, Lakes R, Papadogiannis Y. Viscoelastic properties of low-shrinking composite resins compared to packable composite resins. Dental Materials Journal 2011;30:350-7.

[25] Roeters FJ, de Jong LC, Opdam NJ. Change to a new composite with low shrinkage not sensible at this point. Nederlands Tijdschrift Voor Tandheelkunde 2009;116: 10-5.

[26] Tanno K, Hiraishi N, Otsuki M, Tagami J. Evaluation of cavity adaptation of low-shrinkage composite resin. Asian Pacific Journal of Dentistry 2011;11:27-33.

[27] Kaleem M, Satterthwaite JD, Watts DC. A method for assessing force/work parameters for stickiness of unset resin-composites. Dental Materials 2011;27: 805-10.

[28] Daronch M, Rueggeberg FA, Moss L, de Goes MF. Clinically relevant issues related to preheating composites. Journal of Esthetic and Restorative Dentistry 2006;18:340-51.

[29] Barutcigil C, Yıldız M. Intrinsic and extrinsic discolouration of dimethacrylate and silorane based composites. Journal of Dentistry 2012;40(Suppl. 1):e57-63.

[30] Endo T, Finger WJ, Kanehira M, Utterodt A, Komatsu M. Surface texture and roughness of polished nanofill and nanohybrid resin composites. Dental Materials Journal 2010;29:213-23.

[31] Schmidt M, Kirkevang LL, Hørsted-Bindslev P, Poulsen S Marginal adaptation of a low-shrinkage silorane-based composite: 1-year randomized clinical trial. Clinical Oral Investigations 2011;15:291-5.

[32] van Dijken JW, Lindberg A. Clinical effectiveness of a low-shrinkage resin composite: a five-year evaluation. Journal of Adhesive Dentistry 2009;11:143-8.

[33] Kusgoz A, Ülker M, Yesilyurt C, Yoldas OH, Ozil M, Tanriver M. Silorane-based composite: depth of cure, surface hardness, degree of conversion, and cervical microleakage 
in class II cavities. Journal of Esthetic and Restorative Dentistry 2011;23:324-35.

[34] Flury S, Hayoz S, Peutzfeldt A, Hüsler J, Lussi A. Depth of cure of resin composites: is the ISO 4049 method suitable for bulk fill materials? Dental Materials 2012;28:521-8.

[35] Davidson CL, Feilzer AJ. Polymerization shrinkage and polymerization shrinkage stress in polymer-based restoratives. Journal of Dentistry 1997;25:435-40.

[36] Versluis A, Tantbirojn D, Douglas WH. Do dental composites always shrink toward the light? Journal of Dental Research 1998;77:1435-45.

[37] Lassila LV, Nagas E, Vallittu PK, Garoushi S. Translucency of flowable bulk-filling composites of various thicknesses. Chinese Journal of Dental Research 2012;15:31-5.

[38] Hanabusa M, Mine A, Kuboki T, Momoi Y, Van Ende A, Van Meerbeek B, et al. Bonding effectiveness of a new 'multi-mode' adhesive to enamel and dentine. Journal of Dentistry 2012;40:475-84.

[39] Van Landuyt KL, Peumans M, De Munck J, Cardoso MV, Ermis B, Van Meerbeek B. Three-year clinical performance of a HEMA-free one-step self-etch adhesive in non-carious cervical lesions. European Journal of Oral Sciences 2011;119:511-6.

[40] Van Meerbeek B, De Munck J, Yoshida Y, Inoue S, Vargas M, Vijay P, et al. Buonocore memorial lecture. Adhesion to enamel and dentin: current status and future challenges. Operative Dentistry 2003;28:215-35.

[41] Peumans M, Kanumilli P, De Munck J, Van Landuyt K, Lambrechts P, Van Meerbeek B. Clinical effectiveness of contemporary adhesives: a systematic review of current clinical trials. Dental Materials 2005;21:864-81.

[42] Van Meerbeek B, Van Landuyt K, De Munck J, Hashimoto M, Peumans M, Lambrechts $\mathrm{P}$, et al. Technique-sensitivity of contemporary adhesives. Dental Materials Journal 2005;24:1-13.

[43] De Munck J, Mine A, Poitevin A, Van Ende A, Cardoso MV, Van Landuyt KL, et al. Meta-analytical review of parameters involved in dentin bonding. Journal of Dental Research 2012;91:351-7.

[44] Peutzfeldt A, Asmussen E. The effect of postcuring on quantity of remaining double bonds, mechanical properties, and in vitro wear of two resin composites. Journal of Dentistry 2000;28:447-52.
[45] Ferracane JL, Greener EH. The effect of resin formulation on the degree of conversion and mechanical properties of dental restorative resin. Journal of Biomedical Materials Research 1986;20:121-31.

[46] Frauscher KE, Ilie N. Depth of cure and mechanical properties of nano-hybrid resin-based composites with novel and conventional matrix formulation. Clinical Oral Investigations 2012;16:1425-34.

[47] Kleverlaan CJ, Feilzer AJ. Polymerization shrinkage and contraction stress of dental resin composites. Dental Materials 2005;21:1150-7.

[48] Ilie N, Kunzelmann KH, Hickel R. Evaluation of micro-tensile bond strengths of composite materials in comparison to their polymerization shrinkage. Dental Materials 2006;22:593-601.

[49] McCabe JF, Carrick TE. Output from visible-light activation units and depth of cure of light-activated composites. Journal of Dental Research 1989;68:1534-9.

[50] Musanje L, Darvell BW. Curing-light attenuation in filled-resin restorative materials. Dental Materials 2006;22:804-17.

[51] Czasch P, Ilie N. In vitro comparison of mechanical properties and degree of cure of bulk fill composites. Clinical Oral Investigations 2012,

http://dx.doi.org/10.1007/s00784-012-0702-8.

[52] Oyama K, Tsujimoto A, Otsuka E, Shimizu Y, Shiratsuchi K, Tsubota $\mathrm{K}$, et al. Influence of oxygen inhibition on the surface free energy and enamel bond strength of self-etch adhesives. Dental Materials Journal 2012;31: 26-31.

[53] De Munck J, Arita A, Shirai K, Van Landuyt KL, Coutinho E, Poitevin A, et al. Microrotary fatigue resistance of a HEMA-free all-in-one adhesive bonded to dentin. Journal of Adhesive Dentistry 2007;9:373-9.

[54] D'Arcangelo C, Vanini L, Prosperi GD, Di Bussolo G, De Angelis F, D'Amario M, et al. The influence of adhesive thickness on the microtensile bond strength of three adhesive systems. Journal of Adhesive Dentistry 2009;11:109-15.

[55] Van Landuyt KL, Snauwaert J, De Munck J, Coutinho E, Poitevin A, Yoshida Y, et al. Origin of interfacial droplets with one-step adhesives. Journal of Dental Research 2007;86:739-44. 